Article

\title{
High Energy Storage Density and Impedance Response of PLZT2/95/5 Antiferroelectric Ceramics
}

\author{
Bi Li, Qiuxiang Liu, Xingui Tang *, Tianfu Zhang, Yanping Jiang, Wenhua Li and Jie Luo
}

School of Physics \& Optoelectric Engineering, Guangdong University of Technology, Guangzhou Higher Education Mega Centre, Guangzhou 510006, China; libeiwy@163.com (B.L.); liuqx@gdut.edu.cn (Q.L.); ztf143@163.com (T.Z.); ypjiang@gdut.edu.cn (Y.J.); liwenhuat@gdut.edu.cn (W.L.); jluo@gdut.edu.cn (J.L.)

* Correspondence: xgtang@gdut.edu.cn; Tel.: +86-20-3932-2265

Academic Editor: Lorena Pardo

Received: 23 December 2016; Accepted: 3 February 2017; Published: 8 February 2017

\begin{abstract}
Pb}_{0.97} \mathrm{La}_{0.02}\right)\left(\mathrm{Zr}_{0.95} \mathrm{Ti}_{0.05}\right) \mathrm{O}_{3}$ (PLZT2/95/5) ceramics were successfully prepared via a solid-state reaction route. The dielectric properties were investigated in the temperature region of $26-650{ }^{\circ} \mathrm{C}$. The dielectric diffuse anomaly in the dielectric relaxation was found in the high temperature region of $600-650{ }^{\circ} \mathrm{C}$ with increasing the measuring frequency, which was related to the dynamic thermal process of ionized oxygen vacancies generated in the high temperature. Two phase transition points were detected during heating, which were found to coexist from 150 to $200{ }^{\circ} \mathrm{C}$. Electric field induced ferroelectric to antiferroelectric phase transition behavior of the $\left(\mathrm{Pb}_{0.97} \mathrm{La}_{0.02}\right)\left(\mathrm{Zr}_{0.95} \mathrm{Ti}_{0.05}\right) \mathrm{O}_{3}$ ceramics was investigated in this work with an emphasis on energy storage properties. A recoverable energy-storage density of $0.83 \mathrm{~J} / \mathrm{cm}^{3}$ and efficiency of $70 \%$ was obtained in $\left(\mathrm{Pb}_{0.97} \mathrm{La}_{0.02}\right)\left(\mathrm{Zr}_{0.95} \mathrm{Ti}_{0.05}\right) \mathrm{O}_{3}$ ceramics at $55 \mathrm{kV} / \mathrm{cm}$. Based on these results, $\left(\mathrm{Pb}_{0.97} \mathrm{La}_{0.02}\right)\left(\mathrm{Zr}_{0.95} \mathrm{Ti}_{0.05}\right) \mathrm{O}_{3}$ ceramics with a large recoverable energy-storage density could be a potential candidate for the applications in high energy-storage density ceramic capacitors.
\end{abstract}

Keywords: PLZT2/95/5 ceramics; antiferroelectric; oxygen vacancies; energy storage density

\section{Introduction}

Electrical capacitors display an extremely high powder density but their energy storage density needs further improvement [1-4]. Antiferroelectric (AFE) ceramics are promising candidates for dielectrics in high energy density electrical capacitors due to the reversible electric field-induced AFE to ferroelectric (FE) phase transition [5]. Moreover, $\mathrm{PbZrO}_{3}$-based AFE ceramics have been attracting much attention because of their electric field-induced phase transition between the AFE and FE structures [6]. In the past few years, some efforts have been made to improve the energy storage property of the AFE materials. For example, it was found that the energy storage properties of the $\mathrm{PbZrO}_{3}$ (PZ) materials could be enhanced by doping $\mathrm{La}, \mathrm{Ba}, \mathrm{Nb}$ and Sr elements [7-10]. Lanthanum modified $\mathrm{Pb}\left(\mathrm{Zr}_{0.95} \mathrm{Ti}_{0.05}\right) \mathrm{O}_{3}(\mathrm{PZT} 95 / 5)$ is an excellent candidate material for capacitor applications in nonvolatile ferroelectric random access memory. Microstructure and electrical properties of PLZT2/95/5 ceramics can be improved by powder processing or sintering. Generally, the AFE to FE phase transition in PZ occurs around $225{ }^{\circ} \mathrm{C}$ on heating [11]. The structure of the AFE phase is orthorhombic $\left(A_{O}\right)$ with eight formula units in the unit cell, whereas the FE phase has a rhombohedral structure $\left(F_{\mathrm{R}}\right)$ possibly with two formula units [8]. The $F_{\mathrm{R}}$ phase transforms into a cubic paraelectric $\left(P_{C}\right)$ phase $(\mathrm{PE})$ on heating above $231{ }^{\circ} \mathrm{C}$ [11]. This phase transition of AFE to FE can be induced by varying the temperature [12], electric field [13] or hydrostatic pressure [14]. For example, the stabilization of the AFE and FE phases may be altered by chemical substitutions like 
substitution of $\mathrm{La}^{3+}, \mathrm{Ba}^{2+}, \mathrm{Sr}^{2+}$ at $\mathrm{Pb}^{2+}$-site and $\mathrm{Ti}^{4+}, \mathrm{Sn}^{4+}$ at $\mathrm{Zr}^{4+}$-site in $\mathrm{PZ}$, such as in $\left(\mathrm{Pb}_{1-x} \mathrm{Ba}_{x}\right) \mathrm{ZrO}_{3}$ ceramics, $\mathrm{Pb}_{0.95} \mathrm{Sr}_{0.05}\left(\mathrm{Zr}_{0.5} \mathrm{Ti}_{0.5}\right) \mathrm{O}_{3}$ ceramics, $(\mathrm{Pb}, \mathrm{La})(\mathrm{Zr}, \mathrm{Sn}, \mathrm{Ti}) \mathrm{O}_{3}$ ceramics [8-12].

Currently, the energy-storage behaviors of AFEs in bulk ceramics have attracted increasing attention. Compared with FE materials, AFE materials possess more abundant phase transition behavior, which is larger than those of FE and linear dielectrics $[15,16]$. Based on previous studies, there had been many reports about the energy-storage properties of ceramics, such as Bi-based lead-free piezo-ceramics, $\mathrm{Pb}\left(\mathrm{Mg}_{1 / 3} \mathrm{Nb}_{2 / 3}\right) \mathrm{O}_{3}-\mathrm{PbTiO}_{3}, \quad\left(\mathrm{Bi}_{0.5} \mathrm{Na}_{0.5}\right) \mathrm{TiO}_{3}-\mathrm{Ba}_{0.85} \mathrm{Ca}_{0.15} \mathrm{Ti}_{0.9} \mathrm{Zr}_{0.1} \mathrm{O}_{3}$, $\mathrm{Ba}_{0.95} \mathrm{Ca}_{0.05} \mathrm{Zr}_{0.3} \mathrm{Ti}_{0.7} \mathrm{O}_{3}$, etc. [17-20]. However, the recoverable energy-storage density of previous works is lower than the AFE materials for energy storage ceramic capacitors application.

In this work, high temperature dielectric relaxation behavior was observed in PLZT2/95/5 ceramics, and the relaxation mechanism related oxygen vacancies was discussed. The recoverable energy-storage density calculated from hysteresis loops reached about $0.83 \mathrm{~J} / \mathrm{cm}^{3}$ and efficiency of $70 \%$. These results demonstrated that the $\left(\mathrm{Pb}_{0.97} \mathrm{La}_{0.02}\right)\left(\mathrm{Zr}_{0.95} \mathrm{Ti}_{0.05}\right) \mathrm{O}_{3}$ ceramics may be quite promising candidates for dielectrics in high energy density electrical capacitors due to the reversible electric field-induced FE to AFE phase transition.

\section{Experimental Procedure}

$\left(\mathrm{Pb}_{0.97} \mathrm{La}_{0.02}\right)\left(\mathrm{Zr}_{0.95} \mathrm{Ti}_{0.05}\right) \mathrm{O}_{3}$ (PLZT2/95/5) ceramics were fabricated by a conventional mixed oxide solid-state reaction method. Raw materials of $\mathrm{Pb}_{3} \mathrm{O}_{4}, \mathrm{TiO}_{2}, \mathrm{ZrO}_{2}$ and $\mathrm{La}_{2} \mathrm{O}_{3}$ were weighed according to the formula PLZT2/95/5 in the required stoichiometry with 5 wt \% excess $\mathrm{Pb}_{3} \mathrm{O}_{4}$. Precursor oxides were mixed by ball milling in ethanol for $24 \mathrm{~h}$, then dried and presintered at $850{ }^{\circ} \mathrm{C}$ in an alumina crucible for $5 \mathrm{~h}$. After being remilled and dried, the calcined fine powder with $5 \mathrm{wt} \%$ PVA as a binder was cold pressed into cylindrical pellets of size $12 \mathrm{~mm}$ diameter and 1-2 $\mathrm{mm}$ thickness using a hydraulic press. The ceramics were fabricated by sintering at $1250^{\circ} \mathrm{C}$ for $5 \mathrm{~h}$. In order to avoid the vaporization, $\mathrm{Pb}_{3} \mathrm{O}_{4}$ atmosphere for the sintering was maintained using PZT95/5 as spacer powder.

Ceramic samples were polished to the thickness of $0.8 \mathrm{~mm}$ for the measurement of electrical properties. Both sides of samples were electroded with silver paste and sintered at $650{ }^{\circ} \mathrm{C}$ for $2 \mathrm{~h}$. The crystal structure and orientation of the ceramic samples were characterized by using an X-ray diffractometer (XRD, D/MAX 2200 VPC, Rigaku, Tokyo, Japan) with working current and voltage of $20 \mathrm{~mA}$ and $36 \mathrm{kV}$, respectively. The temperature dependence of dielectric and impedance properties were measured by Agilent E4980A in the temperature range of $26-650{ }^{\circ} \mathrm{C}$ with the heating rate 3 of ${ }^{\circ} \mathrm{C} / \mathrm{min}$. The polarization-electric field $(P-E)$ loops were characterized by Radiant Technologies Precision premier II (Albuquerque, NM, USA) over the temperature range of $30-200{ }^{\circ} \mathrm{C}$.

\section{Results and Discussion}

Figure 1 presents XRD patterns of sintered PLZT2/95/5 ceramics samples. From the XRD patterns, we can observe the additional peaks $\left({ }^{*}\right)$, which matched with the pyrochlore phase. These phases arose due to the volatization of $\mathrm{PbO}$ and over sintering at high temperature [21]. The phase structure of the AFE ceramics was slightly affected by the chemical modification of the PLZT2/95/5 ceramics. It can be seen that the position of the peak (211) shifted to high degrees because the ionic radii of $\mathrm{Pb}^{2+}(0.149 \mathrm{~nm})$ are larger than that of $\mathrm{La}^{3+}(0.136 \mathrm{~nm})$, which indicated smaller lattice parameters of PLZT2/95/5 ceramics.

Temperature dependence of the real $\varepsilon^{\prime}$ and imaginary $\varepsilon^{\prime \prime}$ parts of relative permittivity for PLZT2/95/5 ceramics at various frequencies are plotted in Figure 2. The relative dielectric permittivity $\varepsilon^{\prime}$ displayed almost the same under different frequencies, as we can clearly see in Figure $2 \mathrm{a}$. The relative permittivity curves exhibited anomalous peaks with hollow circles at about $155{ }^{\circ} \mathrm{C}$ and $225{ }^{\circ} \mathrm{C}$, respectively. The small anomalous peak was interpreted by the phase transition AFE to FE [22,23] $\left(T_{\mathrm{O}}=155^{\circ} \mathrm{C}\right)$, whereas the maximum anomalous peak was linked with the transformation of $\mathrm{FE}$ to PE phase $\left(T_{C}=225^{\circ} \mathrm{C}\right)$ at the higher temperature. The samples exhibited FE and AFE coexistence state when $T$ exceeds $T_{o}$ and PE state when $T$ exceeds $T_{C}$ [3]. The dielectric data in Figure 2a were 
maximum for a temperature of about $225^{\circ} \mathrm{C}$, which was in line with the FE curie temperature $\left(T_{C}=225^{\circ} \mathrm{C}\right)$ obtained in PLZT2/95/5 bulk materials [24,25] or about $222^{\circ} \mathrm{C}$ in PLZT2/95/5 thick films [26]. No dielectric peak related to an intermediate transition from the AFE phase to the slim loop FE phase reported in bulk materials can be resolved in the whole temperature range studied [24,25]. In Figure $2 b$, two anomalies in imaginary $\varepsilon^{\prime \prime}$ parts of relative permittivity were observed with hollow circles, which is consistent with the dielectric measurements. The first anomaly occurred near the AFE to FE transition temperature, whereas the second one took place around the FE to PE transition temperature. The similar phenomenon was reported by some researchers [5,22,23]. Moreover, it had been demonstrated using Figure 3 where Figure 3 showed the two states of ferroelectric hysteresis observed in AFE materials. However, it is interesting to note that the value of dielectric loss was very large, and prominent and wide humps were observed in the temperature region of $600-650{ }^{\circ} \mathrm{C}$ from 2 to $20 \mathrm{kHz}$, which were attributed to the space charge polarization or the conductivity of insulating ceramics increases with increase in temperature [27]. The same phenomenon had also been reported in several perovskites with the temperature range of $400-800{ }^{\circ} \mathrm{C}$ [28]. The high temperature relaxation does not have relationship with the phase transitions, which looks like the behavior of the diffuse phase transition. Dielectric relaxation in FE materials is very sensitive to temperature, electric field, ionic substitution, intrinsic defect and domain configuration, because they are able to modify the polarization configuration [29].
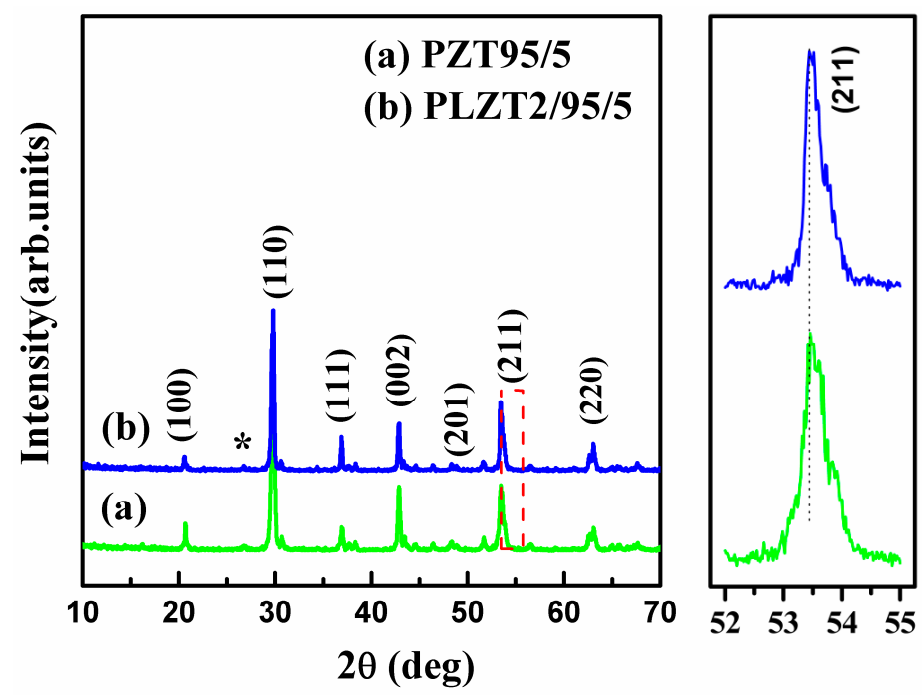

Figure 1. XRD patterns of PLZT2/95/5 ceramics sintered at $1250{ }^{\circ} \mathrm{C}$ for $5 \mathrm{~h}$.
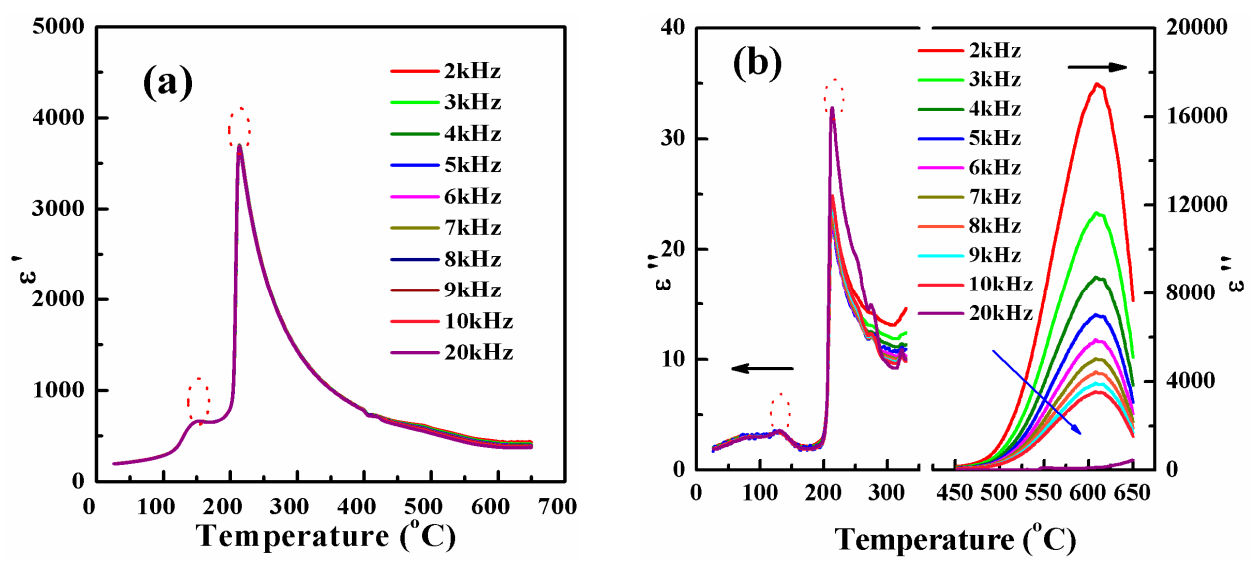

Figure 2. Temperature dependence of the: real $\varepsilon^{\prime}(\mathbf{a})$ and; imaginary $\varepsilon^{\prime \prime}$ (b) parts of the dielectric permittivity for PLZT2/95/5 ceramics at various frequencies. 


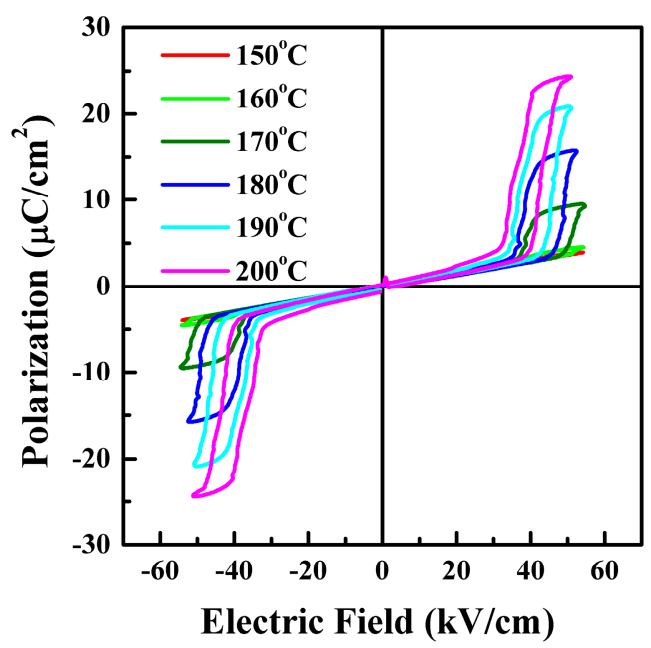

Figure 3. $P$-E hysteresis loops of PLZT2/95/5 ceramics measured at different temperatures but fixed frequency, $10 \mathrm{~Hz}$, under electric field $55 \mathrm{kV} / \mathrm{cm}$.

In order to gain a better study of FE and AFE phase transition behaviors, the hysteresis loops of the PLZT2/95/5 ceramics are shown in Figure 3, which were measured at $10 \mathrm{~Hz}$ at different temperatures. It was clearly seen that temperature played an important role in defining the shape of $P$-E loops. The hysteresis loops were observed with an electric field $55 \mathrm{kV} / \mathrm{cm}$ and this obviously manifested the FE and AFE coexistence phase. For example, $E_{\mathrm{FE}-\mathrm{AFE}}$ declined slightly from 55 to $50 \mathrm{kV} / \mathrm{cm}$, which was attributed to the free energy barrier between FE and AFE with the rising temperature [6]. Under the measurement conditions, the various phase transition field of the ceramics probably contribute to the space charge polarization [30]. The same phenomenon was reported by some researchers [5,22,23], which is followed by a first order reversible AFE to FE phase transformation. The magnitude of the electric field required for the phase change depends on material composition and external parameters such as temperature and stress. Based on these facts (Figures 2 and 3), it can be concluded that the temperature played an important role in describing the shape of $P$-E hysteresis loops, which was ascribed to the AFE to FE phase transition.

Figure 4a illustrates the recoverable energy-storage density $J_{\text {reco }}$ (the blue area) of the PLZT2/95/5 ceramics at $200{ }^{\circ} \mathrm{C}$. Generally, the energy storage density could be estimated from the $P$-E loops, which was calculated with the following equations [31]:

$$
\begin{gathered}
J_{\mathrm{st}}=\int_{0}^{P_{\max }} E d P \quad \text { (upon charging), } \\
J_{\text {reco }}=-\int_{P_{\max }}^{P_{\mathrm{r}}} E d P \quad \text { (upon discharging), }
\end{gathered}
$$

where $E$ is the applied electric field, and $P_{\mathrm{r}}$ and $P_{\max }$ represent the remanent polarization and maximum polarization, respectively. From these equations, it was evident that $J_{\text {reco }}$ values of certain materials could be improved by increasing their operating electric-fields and polarization. For the application of dielectric capacitors in practice, a higher energy-storage efficiency $\eta$ is also always desired. The energy storage efficiency $\eta$ was calculated as the following formula:

$$
\eta=\frac{J_{\text {reco }}}{J_{\text {st }}}=\frac{J_{\text {reco }}}{J_{\text {reco }}+J_{\text {loos }}},
$$

where $J_{\text {loss }}$ is the energy loss density in Figure 4a (the gray area), calculated by the numerical integration of closed area of the hysteresis loops. 

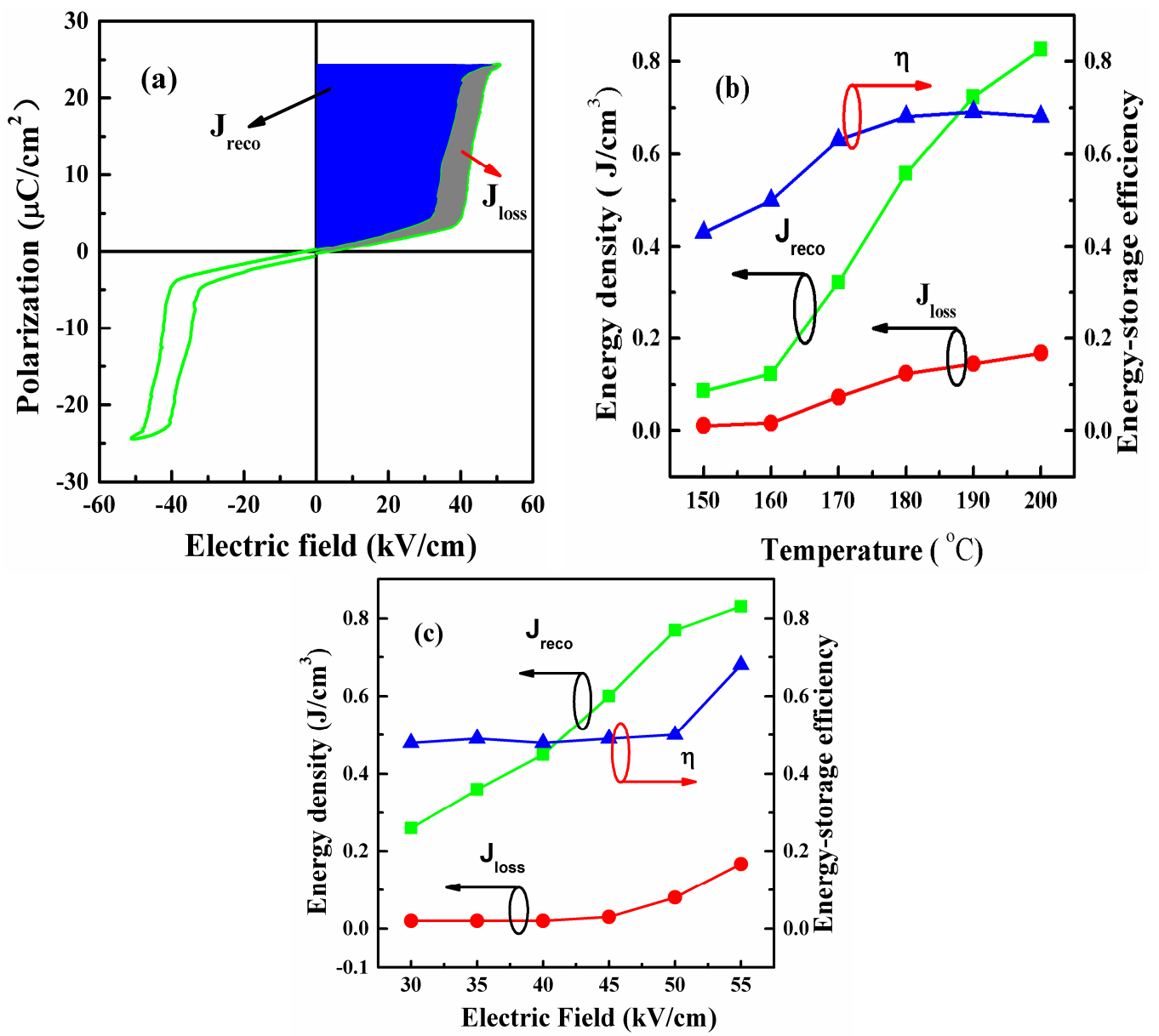

Figure 4. (a) Energy-storage properties of the PLZT2/95/5 ceramics; and (b) the temperature-related; and (c) the electric-field-related showed energy-storage properties of the PLZT2/95/5 ceramics.

The energy storage density and the energy-storage efficiency measured at $10 \mathrm{~Hz}$ are presented in Figure $4 \mathrm{~b}$, which were obtained from Figure 3 at $55 \mathrm{kV} / \mathrm{cm}$ at different temperatures. AFE materials possess relatively larger energy storage density, have lower values of remnant polarization and coercive electric field and faster discharge rates for dissipating stored electrical energy, due to AFE to FE phase transition [32]. However, the anti-parallel dipoles are aligned to form a FE phase at higher electric fields. Therefore, the temperature dependence of the energy storage performance is also a very important parameter over the measurement range. For example, the $J_{\text {reco }}$ value for the PLZT2/95/5 ceramics was changed from 0.12 to $0.83 \mathrm{~J} / \mathrm{cm}^{3}$, and the corresponding $\eta$ value was varied from $40 \%$ to $70 \%$, showing temperature stability of the energy storage performance. In practical application, people often desire a higher energy-storage efficiency $\eta$ and lower energy-loss density $J_{\text {loss }}$. Figure $4 \mathrm{c}$ illustrates the energy-storage density and energy storage efficiency of these samples as a function of the operating electric fields, which were measured from 30 to $55 \mathrm{kV} / \mathrm{cm}$ at $10 \mathrm{~Hz}$. Clearly, it can be seen that the PLZT2/95/5 ceramics displayed the largest $J_{\text {reco }}$ values and has the lowest $J_{\text {loss }}$ values over the measurement range. For example, the $J_{\text {reco }}$ value for the PLZT2/95/5 ceramics was varied from 0.28 to $0.83 \mathrm{~J} / \mathrm{cm}^{3}$, and the corresponding $\eta$ value was varied from $40 \%$ to $70 \%$ as the electric field increases from 30 to $55 \mathrm{kV} / \mathrm{cm}$. Under the same conditions of applied electric field, the experimental data showed much higher values of $J_{\text {reco }}$ than those reported in $\mathrm{BaTiO}_{3}-\mathrm{SrTiO}_{3}$ composites, $\mathrm{BaSrTiO}_{3}$ ceramics, and $\mathrm{BaTiO}_{3}$ ceramics [33-35]. However, owing to the fact that these measurements are done by immersing the ceramics in silicone oil which breaks down at temperatures beyond $200^{\circ} \mathrm{C}, P-E$ data were taken from 30 to $200^{\circ} \mathrm{C}$ (which was less than the transition temperature). Hence, energy storage properties over $200^{\circ} \mathrm{C}$ have not been obtained. 
In order to analyze the high temperature dielectric behavior, impedance analysis is conducted as a powerful technique which has been effectively used for probing into electrical properties of the electro-ceramic materials, such as conductivity, dielectric behavior and relaxation characteristic [36,37]. The samples at different temperatures only one high frequency semicircular arc are shown in Figure $5 \mathrm{a}$. With the increasing temperature, a single semicircular arc had been observed and the radius of semicircles decreased, which illustrated a strong temperature dependence resistance. The mobility of the space charge became easier with the increasing temperature, the accumulated charge carriers in the vicinity of phase boundaries had sufficient energy to pass through the barrier, leading to an enhanced conductivity with the reduction in impedance [18]. The Nyquist plot showed a tail at lower frequencies, indicating the contact effect come into action, the similar phenomenon is also observed in $\mathrm{SmAlO}_{3}$ ceramics [38].
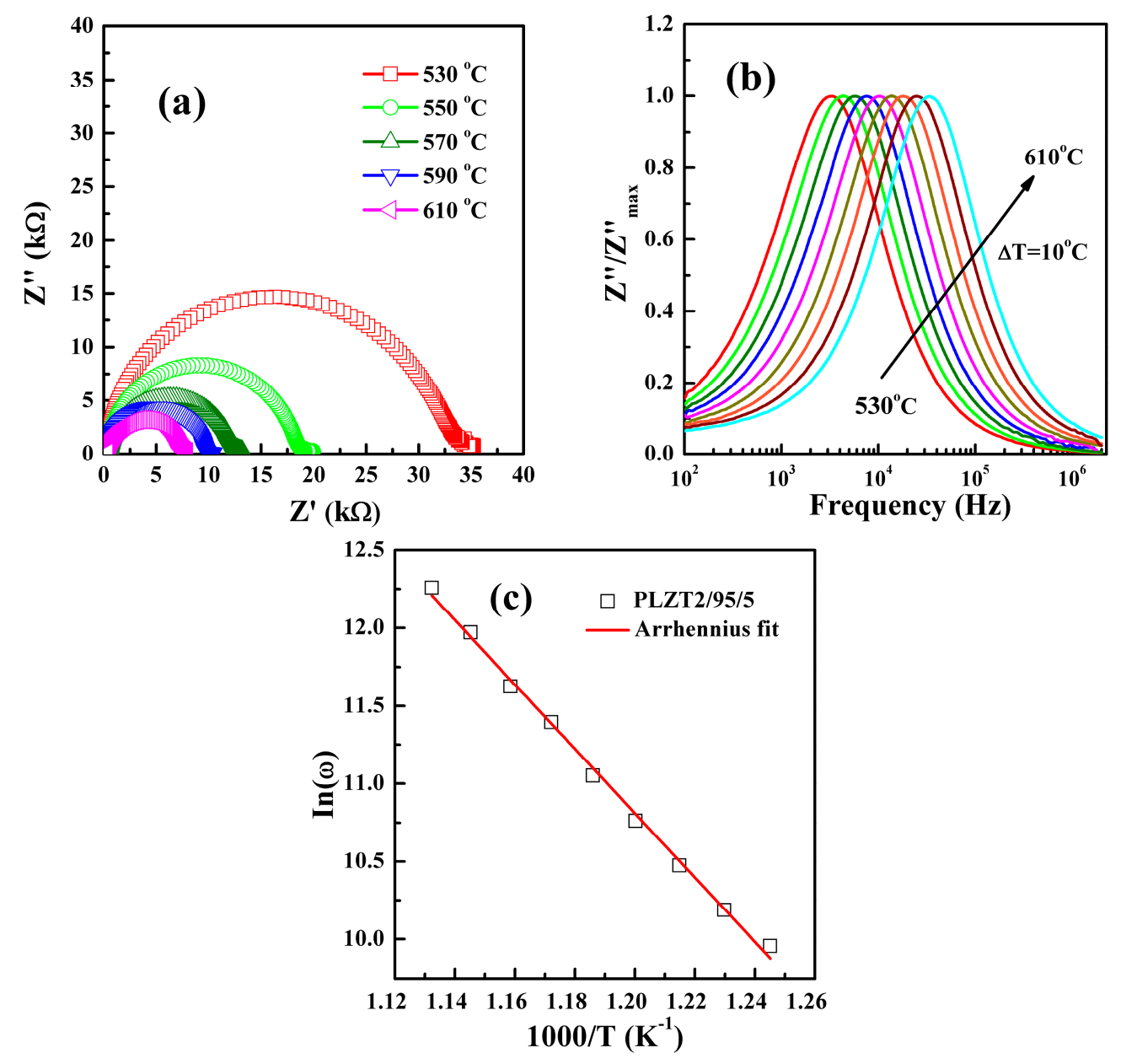

Figure 5. (a) Cole-Cole plots for PLZT2/95/5 ceramics at different temperatures; (b) complex impedance plots of $Z^{\prime \prime} / Z^{\prime \prime}{ }_{\text {max }}$ at different temperatures; and (c) $\ln (\omega)$ versus $1000 /$ curves for ceramics. The straight lines were used to fit the Arrhenius law.

The variation of normalized imaginary part of impedance $\left(Z^{\prime \prime} / Z^{\prime \prime}{ }_{\max }\right)$ with frequency at different temperatures is shown in Figure $5 b$. The $Z^{\prime \prime} / Z^{\prime \prime}{ }_{\max }$ value exhibited a peak at each temperature and moved to higher frequency with increasing temperature, which can be as an evidence of hopping mechanism, in which the numbers of polaron will gradually decrease as it hopped with gradual decrease of electron lattice coupling [39]. In perovskite materials, the major mode of charge transport 
is multiple hopping processes. For a thermally activated relaxation process, the activation energy of relaxation units can be calculated by the famous Arrhenius law [40]:

$$
\omega_{p}=\omega_{0} \times \exp \left(-\frac{E_{a}}{k_{\beta} T}\right),
$$

where $T, \omega_{0}, E_{a}$, and $k_{\beta}$ are the absolute temperature, characteristic frequency, activation energy, and the Boltzmann constant, respectively. The experimental data were fitted with the above equation, as shown in Figure 5c. For PLZT2/95/5 ceramics, the activation energy $E_{a}$ was about $1.61 \mathrm{eV}$. Based on our result of $E_{a}$ value, it can be reasonably concluded that the high-temperature dielectric behavior of PLZT2/95/ 5 ceramics may be ascribed to the dynamic thermal process of ionized OVs [39]. The results were coincided well with the dielectric behavior observed in the temperature of the dielectric spectrum. It is widely accepted that grain boundaries represent barriers of a certain height for the migration of OVs [41]. The movement of OVs is not localized in one unit cell; it can extend to the whole sample and give an ionic conductivity [42,43]. The OVs activated process is mainly dependent on temperature. Conduction induced by OVs becomes dominant with the increasing in temperature and frequency, because the mobility of oxygen ions becomes higher in high temperature region [29]. It is the significant increase in dielectric loss in the high temperature and lower frequency region, which is interpreted by the dynamic thermal process of ionized OVs. Therefore, it was concluded that the high temperature dielectric relaxation behavior may be associated with the migration of OVs in PLZT2/95/5 ceramics.

\section{Conclusions}

In summary, PLZT2/95/5 ceramics were successfully prepared by a conventional mixed oxide solid-state reaction method. The hysteresis loops were observed in temperature range of $150-200{ }^{\circ} \mathrm{C}$, where FE and AFE were found to coexist. The high temperature dielectric relaxation behaviors related to OVs of PLZT2/95/ 5 ceramics were investigated, and the relaxation behavior was analyzed with activation energy about $1.61 \mathrm{eV}$. Based on our result of $E_{a}$ value, it can be reasonably concluded that the high-temperature dielectric behavior of PLZT2/95/5 ceramics may be ascribed to the dynamic thermal process of ionized OVs. The energy-storage density and efficiency calculated from hysteresis loops achieved about $0.83 \mathrm{~J} / \mathrm{cm}^{3}$ and $70 \%$, respectively. It indicated that these PLZT2/95/5 ceramics may be a promising material for energy storage ceramic capacitors applications.

Acknowledgments: This work was supported by the National Natural Science Foundation of China (Grant Nos. 11574057 and 51604087); the Guangdong Provincial Natural Science Foundation of China (Grant No. 2016A030313718); the Science and Technology Program of Guangdong Province of China (Grant No. 2016A010104018); and the Youth Foundation of Guangdong University of Technology (Grant No. 14QNZA004).

Author Contributions: Xingui Tang conceived and designed the experiments, analyzed and interpreted the data. Bi Li prepared the samples, preformed the structural, ferroelectric, dielectric and impedance measurements and, together with Qiuxiang Liu, Tianfu Zhang, Yanping Jiang, Wenhua Li and Jie Luo, primarily analyzed the experimental data. Bi Li and Xingui Tang wrote the manuscript. All authors commented on the manuscript.

Conflicts of Interest: The authors declare no conflict of interest.

\section{References}

1. Singh, K. Antiferroelectric lead zirconate. A material for energy storage. Ferroelectrics 1989, 94, 433. [CrossRef]

2. Young, S.; Zhang, J.; Hong, W.; Tan, X. Mechanical self-confinement to enhance energy storage density of antiferroelectric capacitors. J. Appl. Phys. 2013, 113, 054101. [CrossRef]

3. Liu, Z.; Chen, X.; Peng, W.; Xu, C.; Dong, X.; Gao, F.; Wang, G. Temperature-dependent stability of energy storage properties of $\mathrm{Pb}_{0.97} \mathrm{La}_{0.02}\left(\mathrm{Zr}_{0.58} \mathrm{Sn}_{0.335} \mathrm{Ti}_{0.085}\right) \mathrm{O}_{3}$ antiferroelectric ceramics for pulse power capacitors. Appl. Phys. Lett. 2015, 106, 262901. [CrossRef]

4. Chen, S.; Wang, X.; Yang, T.; Wang, J. Composition-dependent dielectric properties and energy storage performance of $(\mathrm{Pb}, \mathrm{La})(\mathrm{Zr}, \mathrm{Sn}, \mathrm{Ti}) \mathrm{O}_{3}$ antiferroelectric ceramics. J. Electroceram. 2014, 32, 307-310. [CrossRef] 
5. Chauhan, A.; Patel, S.; Vaish, R.; Bowen, C. Anti-ferroelectric ceramics for high energy density capacitors. Materials 2015, 8, 8009-8031. [CrossRef]

6. Bharadwaja, S.; Krupanidhi, S. Backward switching phenomenon from field forced ferroelectric to antiferroelectric phases in antiferroelectric $\mathrm{PbZrO}_{3}$ thin films. J. Appl. Phys. 2001, 89, 4541-4547. [CrossRef]

7. Ma, B.; Kwon, D.; Narayanan, M.; Balachandran, U. Dielectric properties and energy storage capability of antiferroelectric $\mathrm{Pb}_{0.92} \mathrm{La}_{0.08} \mathrm{Zr}_{0.95} \mathrm{Ti}_{0.05} \mathrm{O}_{3}$ film-on-foil capacitors. J. Mater. Res. 2009, 24, 2993-2996. [CrossRef]

8. Pokharel, B.; Pandey, D. Dielectric studies of phase transitions in $\mathrm{Pb}_{1-x} \mathrm{Ba}_{x} \mathrm{ZrO}_{3}$. J. Appl. Phys. 2000, 88, 5364-5373. [CrossRef]

9. Silva, P.; Venet, M.; Florencio, O. Influence of diffuse phase transition on the an elastic behavior of $\mathrm{Nb}$-doped $\mathrm{Pb}\left(\mathrm{Zr}_{0.53} \mathrm{Ti}_{0.47}\right) \mathrm{O}_{3}$ ceramics. J. Alloys Compd. 2015, 647, 784-789. [CrossRef]

10. Kumar, N.; Tirupathi, P.; Kumar, B.; Pastor, M.; Pandey, A.; Choudhary, R. Observation of dielectric relaxor behavior in $\mathrm{Pb}_{0.95} \mathrm{Sr}_{0.05}\left(\mathrm{Zr}_{0.5} \mathrm{Ti}_{0.5}\right) \mathrm{O}_{3}$ ceramics. Adv. Mater. Lett. 2015, 64, 284-289. [CrossRef]

11. Pokharel, B.; Ranjan, R.; Pandey, D.; Siruguri, V.; Paranjpe, S. Rhombohedral superlattice structure and relaxor ferroelectric behavior of $\left(\mathrm{Pb}_{0.70} \mathrm{Ba}_{0.30}\right) \mathrm{ZrO}_{3}$ ceramics. Appl. Phys. Lett. 1999, 74, 756-758. [CrossRef]

12. Zhang, T.; Tang, X.; Liu, Q.; Jiang, Y.; Huang, X. Oxygen-vacancy-related high temperature dielectric relaxation in $\left(\mathrm{Pb}_{1-x} \mathrm{Ba}_{x}\right) \mathrm{ZrO}_{3}$ ceramics. J. Am. Ceram. Soc. 2015, 98, 551-558. [CrossRef]

13. Yang, T.; Yao, X. Effect of compositional variations on field-induced phase transition of $(\mathrm{Pb}, \mathrm{La})(\mathrm{Zr}, \mathrm{Sn}, \mathrm{Ti}) \mathrm{O}_{3}$ antiferroelectric ceramics. Ferroelectrics 2007, 355, 71-76. [CrossRef]

14. Dai, Z.; Xu, Z.; Yao, X. Effect of dc bias on pressure-induced depolarization of $\mathrm{Pb}(\mathrm{Nb}, \mathrm{Zr}, \mathrm{Sn}, \mathrm{Ti}) \mathrm{O}_{3}$ ceramics. Appl. Phys. Lett. 2008, 92, 072904. [CrossRef]

15. Xu, B.; Moses, P.; Pai, N.; Cross, L. Charge release of lanthanum-doped lead zirconate titanate stannate antiferroelectric thin films. Appl. Phys. Lett. 1998, 72, 593-595. [CrossRef]

16. Mirshekarloo, M.; Yao, K.; Sritharan, T. Large strain and high energy storage density in orthorhombic perovskite, $\left(\mathrm{Pb}_{0.97} \mathrm{La}_{0.02}\right)\left(\mathrm{Zr}_{1-x-y} \mathrm{Sn}_{x} \mathrm{Ti}_{y}\right) \mathrm{O}_{3}$ antiferroelectric thin films. Appl. Phys. Lett. 2010, 97, 142902. [CrossRef]

17. Malik, R.; Hussain, A.; Maqbool, A.; Zaman, A.; Song, T.; Kim, W.; Kim, M. Giant strain, thermally-stable high energy storage properties and structural evolution of Bi-based lead-free piezoceramics. J. Alloys Compd. 2016, 682, 302-310. [CrossRef]

18. Zhang, T.; Tang, X.; Liu, Q.; Jiang, Y.; Huang, X.; Zhou, Q. Energy-storage properties and high-temperature dielectric relaxation behaviors of relaxor ferroelectric $\mathrm{Pb}\left(\mathrm{Mg}_{1 / 3} \mathrm{Nb}_{2 / 3}\right) \mathrm{O}_{3}-\mathrm{PbTiO}_{3}$ ceramics. J. Appl. D Appl. Phys. 2016, 49, 095302. [CrossRef]

19. Pu, Y.; Yao, M.; Liu, H.; Fromling, T. Phase transition behavior, dielectric and ferroelectric properties of $(1-x)\left(\mathrm{Bi}_{0.5} \mathrm{Na}_{0.5}\right) \mathrm{TiO}_{3-x} \mathrm{Ba}_{0.85} \mathrm{Ca}_{0.15} \mathrm{Ti}_{0.9} \mathrm{Zr}_{0.1} \mathrm{O}_{3}$ ceramics. J. Eur. Ceram. Soc. 2016, 36, 2461-2468. [CrossRef]

20. Zhan, D.; Xu, Q.; Huang, D.; Liu, H.; Chen, W.; Zhang, F. Dielectric nonlinearity and electric breakdown behaviors of $\mathrm{Ba}_{0.95} \mathrm{Ca}_{0.05} \mathrm{Zr}_{0.3} \mathrm{Ti}_{0.7} \mathrm{O}_{3}$ ceramics for energy storage utilizations. J. Alloys Compd. 2016, 682, 594-600. [CrossRef]

21. Zhang, G.; Chen, Z.; Fan, B.; Liu, J.; Chen, M.; Shen, M.; Liu, P.; Zeng, Y.; Jiang, S.; Wang, Q. Large enhancement of the electrocaloric effect in PLZT ceramics prepared by hot-pressing. APL Mater. 2016, 4, 064103. [CrossRef]

22. Wawrzała, P.; Korzekwa, J. Charge-discharge properties of PLZT x/90/10 ceramics. Ferroelectrics 2013, 446, 91-101. [CrossRef]

23. Ciuchi, I.; Mitoseriu, L.; Galassi, C. Antiferroelectric to ferroelectric crossover and energy storage properties of $\left(\mathrm{Pb}_{1-x} \mathrm{Lax}\right)\left(\mathrm{Zr}_{0.90} \mathrm{Ti}_{0.10}\right)_{1-x / 4} \mathrm{O}_{3}(0.02 \leq x \leq 0.04)$ ceramics. J. Am. Ceram. Soc. 2016, 99, 2382-2387. [CrossRef]

24. Dai, X.; Viehland, D. Effects of lanthanum modification on the antiferroelectric-ferroelectric stability of high zirconium content lead zirconate titanate. J. Appl. Phys. 1994, 76, 3701-3709. [CrossRef]

25. Xu, Z.; Dai, X.; Viehland, D. Impurity-induced incommensuration in antiferroelectric La-modified lead zirconate titanate. Phys. Rev. B 1995, 51, 6261-6271. [CrossRef]

26. Hao, X.; Yue, Z.; Xu, J.; An, S.; Nan, C. Energy-storage performance and electrocaloric effect in (100)-oriented $\mathrm{Pb}_{0.97} \mathrm{La}_{0.02}\left(\mathrm{Zr}_{0.95} \mathrm{Ti}_{0.05}\right) \mathrm{O}_{3}$ antiferroelectric thick films. J. Appl. Phys. 2011, 110, 064109. [CrossRef]

27. Sukkha, U.; Vittayakorn, W.; Muanghlua, R.; Niemcharoen, S.; Boonchom, B.; Vittayakorn, N. Phase transition behavior of the $(1-x) \mathrm{PbZrO}_{3}-x \mathrm{Ba}\left(\mathrm{Al}_{1 / 2} \mathrm{Nb}_{1 / 2}\right) \mathrm{O}_{3}$ solid solution. J. Am. Ceram. Soc. 2012, 95, 3151-3157. [CrossRef] 
28. Bidault, O.; Goux, P.; Kchikech, M.; Belkaoumi, M.; Maglione, M. Space-charge relaxation in perovskites. Phys. Rev. B 1994, 49, 7868-7873. [CrossRef]

29. Singh, G.; Tiwari, V.; Gupta, P. Role of oxygen vacancies on relaxation and conduction behavior of $\mathrm{KNbO}_{3}$ ceramic. J. Appl. Phys. 2010, 107, 064103. [CrossRef]

30. Ye, M.; Sun, Q.; Chen, X.; Jiang, Z.; Wang, F. Electrical and energy storage performance of Eu-doped $\mathrm{PbZrO}_{3}$ thin films with different gradient sequences. J. Am. Ceram. Soc. 2012, 95, 1486-1488. [CrossRef]

31. Chu, B.; Zhou, X.; Ren, K.; Neese, B.; Lin, M.; Wang, Q.; Bauer, F.; Zhang, Q. A dielectric polymer with high electric energy density and fast discharge speed. Science 2006, 313, 1887. [CrossRef] [PubMed]

32. Patel, S.; Chauhan, A.; Vaish, R. Enhancing electrical energy storage density in anti-ferroelectric ceramics using ferroelastic domain switching. Mater. Res. Express 2014, 1, 045502. [CrossRef]

33. Yu, D.; Xu, N.; Hu, L.; Zhang, Q.; Yang, H. Nanocomposites with $\mathrm{BaTiO}_{3}-\mathrm{SrTiO}_{3}$ hybrid fillers exhibiting enhanced dielectric behaviours and energy-storage densities. J. Mater. Chem. C 2015, 3, 4016-4022. [CrossRef]

34. Wang, Y.; Shen, Z.; Li, Y.; Wang, Z.; Luo, W.; Hong, Y. Optimization of energy storage density and efficiency in $\mathrm{Ba}_{x} \mathrm{Sr}_{1-x} \mathrm{TiO}_{3}(x \leq 0.4)$ paraelectric ceramics. Ceram. Int. 2015, 41, 8252-8256. [CrossRef]

35. Patel, S.; Chauhan, A.; Vaish, R. Improved electrical energy storage density in Vanadium-doped $\mathrm{BaTiO}_{3}$ bulk ceramics by addition of $3 \mathrm{BaO}-3 \mathrm{TiO}_{2}-\mathrm{B}_{2} \mathrm{O}_{3}$ glass. Energy Technol. 2015, 3, 70-76. [CrossRef]

36. Chen, D.; Tang, X.; Liu, Q.; Jiang, Y.; Ma, C.; Li, R. Impedance response and dielectric relaxation in Co-precipitation derived ferrite (Ni,Zn)Fe ${ }_{2} \mathrm{O}_{4}$ ceramics. J. Appl. Phys. 2013, 113, 214110. [CrossRef]

37. Gonzalez, A.; García, A.; Benavente-Peces, C.; Pardo, L. Revisiting the characterization of the losses in piezoelectric materials from impedance spectroscopy at resonance. Materials 2016, 9, 72. [CrossRef]

38. Lei, C.; Wang, C.; Li, T.; Wang, G.; Sun, X.; Liu, L.; Wang, J. Dielectric relaxations and phase-transition-like behavior in $\mathrm{SmAlO}_{3}$ ceramics at high temperatures. J. Mater. Sci. 2013, 48, 7294-7299. [CrossRef]

39. Chen, F.; Liu, Q.; Tang, X.; Jiang, Y.; Yue, J.; Li, J. Diffuse phase transition and high-temperature dielectric relaxation study on $\left(\mathrm{Bi}_{0.5} \mathrm{Na}_{0.5}\right)_{1-x} \mathrm{Ba}_{x} \mathrm{TiO}_{3}$ ceramics. Physica B 2016, 496, 20-25. [CrossRef]

40. Li, J.; Tang, X.; Zhang, T.; Liu, Q.; Jiang, Y.; Yue, J. Impedance response and high temperature dielectric relaxation behavior in lead barium strontium zirconate ceramics. J. Mater. Sci. Mater. Electron. 2016, 27, 1582-1589. [CrossRef]

41. Waser, R.; Baiatu, T.; Hardtl, K. Dc electrical degradation of perovskite-type titanates: I Ceramics. J. Am. Ceram. Soc. 1990, 73, 1645-1653. [CrossRef]

42. Wang, J.; Tang, X.; Chan, H.; Choy, C. Dielectric relaxation and electrical properties of $0.94 \mathrm{~Pb}\left(\mathrm{Fe}_{1 / 2} \mathrm{Nb}_{1 / 2}\right) \mathrm{O}_{3}-$ $0.06 \mathrm{PbTiO}_{3}$ single crystals. Appl. Phys. Lett. 2005, 86, 152907. [CrossRef]

43. Scott, J.; Dawber, M. Oxygen-vacancy ordering as a fatigue mechanism in perovskite ferroelectrics. Appl. Phys. Lett. 2000, 76, 3801-3803. [CrossRef] 